\title{
RADIOCARBON REVEALS THE AGE OF TWO PRECIOUS TOMBS IN THE ETRUSCAN SITE OF POPULONIA-BARATTI (TUSCANY)
}

\author{
C Scirè Calabrisotto ${ }^{1} \cdot \mathrm{M} \mathrm{E} \mathrm{Fedi}^{2,3} \cdot \mathrm{F} \mathrm{Taccetti}^{2} \cdot \mathrm{M} \mathrm{Benvenuti}^{4} \cdot$ L Chiarantini $^{4} \cdot$ L Quaglia $^{5}$
}

\begin{abstract}
The archaeological site of Populonia-Baratti, in the southern part of Tuscany (Italy), was one of the most important centers in ancient Etruria, as seen in the evidence of metallurgical activities carried out at that time. During recent archaeological excavations (2005) in the ancient industrial area of Populonia, along the Baratti beach, 2 interesting tombs were found. The 2 graves were unusually located in an area dedicated to metallurgical activity and showed a particular structure of the burial chambers and an extreme richness in the grave goods. The unique character of the 2 tombs prompted many questions: who were these 2 individuals (a woman wearing many jewels and a tall, vigorous man) and when did they die? In order to obtain useful information about the chronology of the 2 tombs, accelerator mass spectrometry (AMS) radiocarbon analyses were performed on samples taken from the ribs of the 2 skeletons. Measured ${ }^{14} \mathrm{C}$ ages were converted to calibrated ages using additional information derived from stable isotope ratios measured in the extracted collagen. Actually, the ${ }^{13} \mathrm{C}$ data provided useful hints about the diet of the 2 individuals, thus allowing us to estimate the percentage of marine food consumed (about $30 \%$ ) and exploit a combined marine-terrestrial calibration curve. As a result, the age of the 2 individuals can be dated to the 2nd century AD, during Roman times, which is in good agreement with the information obtained from archaeological, anthropological, and stylistic studies of the 2 tombs.
\end{abstract}

\section{INTRODUCTION}

The archaeological site of Populonia-Baratti is one of the most important Etruscan sites of southern Tuscany (see Figure 1). The ancient town of Poulonia was the only Etruscan settlement built directly on the sea, and it became one of the most significant metalworking centers of Europe in the 1st millennium $\mathrm{BC}$, thanks to its strategic location midway between the large iron deposits of Elba Island and the polymetallic ores $(\mathrm{Cu}, \mathrm{Sn}, \mathrm{Pb}$, etc.) of the southern Tuscany districts.

Ancient Populonia stretched over 80 hectares between the Piombino Promontory and the Baratti Gulf. It was divided into 2 parts: the upper city with temples and residential buildings (Acropolis) on the summit of the promontory, and the lower city, including the maritime port and the sepulchral areas. The industrial areas for metallurgical activities were located outside the town's defensive walls, close to the harbor zone. The iron ores (mostly hematite) from nearby Elba Island were probably processed near the beach, where metallurgical evidence and several forges have been found as proof that iron-working activity was performed in this area (Chiarantini et al. 2006; Cartocci et al. 2007). In fact, metal production, first related to copper working, is already well documented in the region since the 7th century BC. Iron production peaked between the 6th and 4th century BC, allowing the commercial hegemony of Populonia to continue for many centuries. Populonia fell under Roman rule in the course of the 3rd century $\mathrm{BC}$, but this apparently did not cause a significant decline of iron production, which actually seems to cease in the 1st century AD. However, according to archaeological evidence, Populonia remained a strategic site due to its commercial roots until the end of 4th century AD (Fedeli et al. 1993).

Since 2002, several archaeological campaigns (in collaboration with Soprintendenza per i Beni Archeologici della Toscana and Società Parchi Val di Cornia S.p.a.) have been carried out in the Baratti beach area in order to reconstruct ancient metallurgical activities in the industrial area of Populonia. During one of the most recent excavations (September-November 2005), 2 valuable

\footnotetext{
${ }^{1}$ Dipartimento di Fisica dell'Università di Firenze, via Sansone 1, 50019 Sesto Fiorentino (Fi), Italy.

${ }^{2}$ INFN Sezione di Firenze, via Sansone 1, 50019 Sesto Fiorentino (Fi), Italy.

${ }^{3}$ Corresponding author. Email: fedi@fi.infn.it.

${ }^{4}$ Dipartimento di Scienze della Terra dell'Università di Firenze, via La Pira 4, 50125 Firenze, Italy.

${ }^{5}$ Dipartimento di Archeologia e Storia delle Arti, Università di Siena, Via Roma 56, 53100 Siena, Italy.
} 


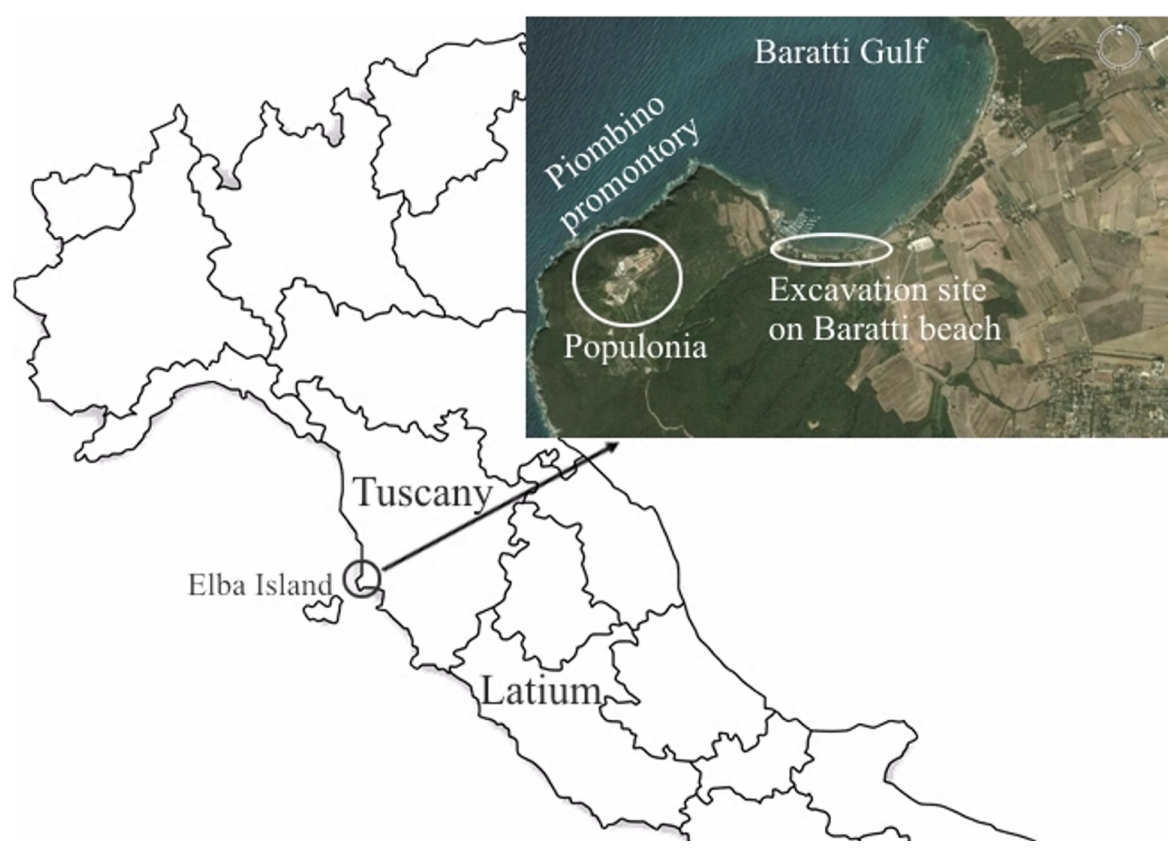

Figure 1 Location of the archaeological site of Populonia-Baratti in southern Tuscany

tombs, Tombs XI and XII, were found. The presence of several Etruscan necropolises is well documented at Populonia. Nevertheless, these 2 tombs appeared to be quite uncommon for their unusual position (in the metalworking area close to the forges, as shown in Figure 2), for the particular structure of burial chambers, and for the richness of the grave goods.

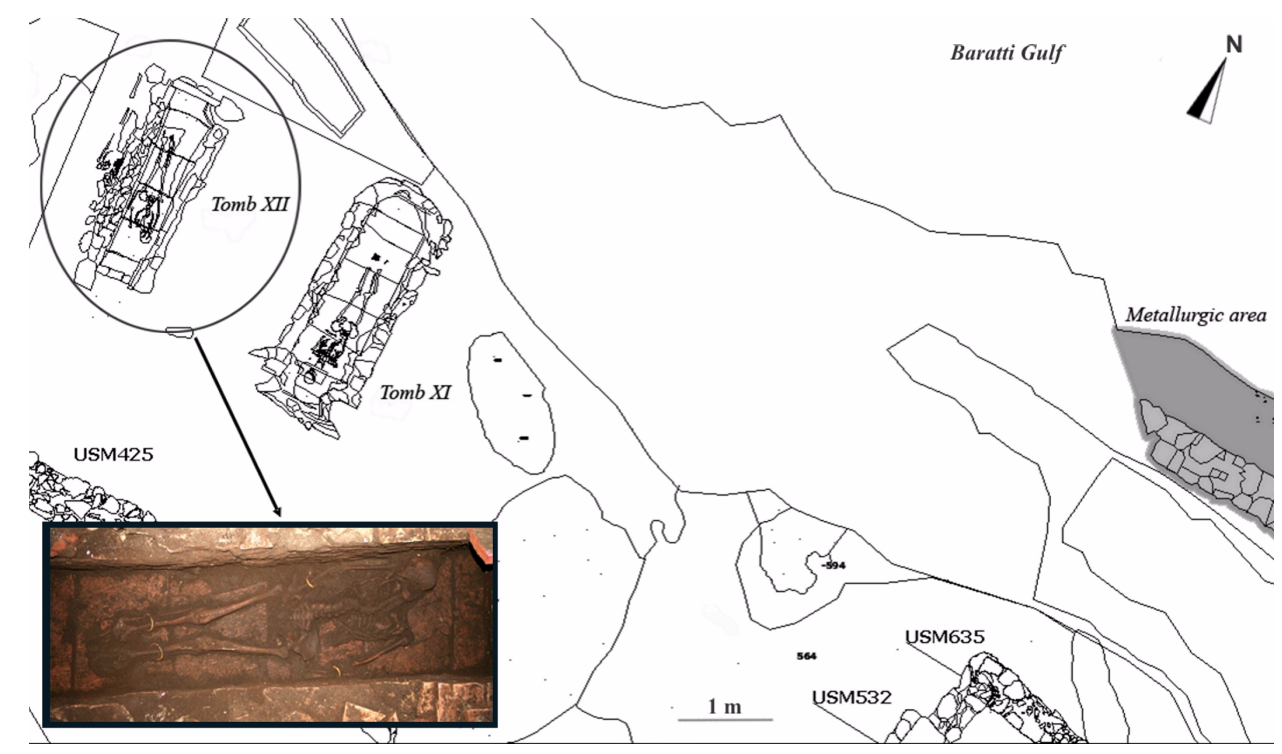

Figure 2 Portion of the site investigated in the archaeological campaign of September-November 2005. A photograph of the skeleton found in Tomb XII is given in the lower-left inset. 
Due to the unique character of the 2 tombs, a detailed research program was developed in order to reconstruct their chronological, anthropological, and stylistic contexts. Anthropological investigations of the skeletons together with archaeological studies on the tombs' structure and the grave goods provided useful but rough information about the period when the 2 individuals died. Thus, radiocarbon was also chosen to complete the dating; in this paper, we present these results.

\section{ARCHAEOLOGICAL AND ANTHROPOLOGICAL FEATURES OF TOMBS XI AND XII}

As discussed in the previous section, just after their recovery, Tomb XI and Tomb XII were considered of remarkable archaeological significance for several reasons. The unusual location of the 2 tombs was quite puzzling; as illustrated in Figure 2, they were found very near the area devoted to metallurgical activities. Moreover, the 2 structures were isolated findings, quite far from the Etruscan, Roman, or Medieval sepulchral areas.

The structure of the graves was quite uncommon too: no analogous burial structures have been found in the archaeological site. Both tombs were marked on the ground level by 2 big tombstones that probably acted as grave segnacolo (marker). The topsoil contexts of the 2 structures were characterized by small- and medium-sized stones bound with lime mortar; the burial chambers were built with clay bricks and covered by a double sloping roof composed of bricks and tiles forming a structure similar to the so-called "cappuccina" tomb.

Tomb XI contained a male individual, lying supine with the arms resting on his belly. This tomb was quite large and, through anthropological analyses (Botarelli et al. 2007), the height of the male $(\sim 1.72 \mathrm{~m})$ was estimated; his tallness clearly distinguishes him from the shorter mean height values of ancient peoples. Tomb XII contained a female individual lying in a similar body position; the skeleton was lying supine with the arms along the trunk, hands on the hips, and stretched legs (see Figure 2 inset). The dimensions of the tomb structure were similar to Tomb XI; the female's height was estimated as about $1.65 \mathrm{~m}$.

The funeral equipment of Tomb XI was composed of 2 ceramic objects placed at the feet of the body and a glass object, probably a balsamarium, whose fragments were recovered close to the knees. The skull of the individual was lying on a tile simulating a pillow. A coin (see Figure 3a) was found originally placed in its mouth. The funerary goods of Tomb XII were incredibly rich. Three ceramic containers for liquids (olpi) were placed at the feet of the body. They were very similar to the ceramic findings of Tomb XI and represented ceramic tools for everyday use. An oil lamp with vine nut decorations was found as well. The outstanding richness of the funerary goods was represented by several gold jewels with gemstones (see Figure 3b): 1 necklace, 2 bracelets, 2 rings, and 2 ankle bracelets.

On the basis of anthropological and archaeological evidence, the tombs might be roughly dated back to the Roman Empire; in particular, the figure marked on the coin found in Tomb XI was attributed to the Roman Emperor Marco Aurelio (AD 161-180) (Botarelli et al. 2007).

${ }^{14} \mathrm{C}$ measurements were performed on 6 bone samples collected from the ribs of the 2 individuals: T11_A, T11_B, T11_C (from the male skeleton of Tomb XI) and T12_A, T12_B, T12_C (from the female skeleton of Tomb XII).

\section{AMS RADIOCARBON MEASUREMENTS}

All collected samples were prepared and measured by AMS at the LABEC (Laboratorio di tecniche nucleari per i Beni Culturali) laboratory of INFN (Istituto Nazionale di Fisica Nucleare) in Florence. 

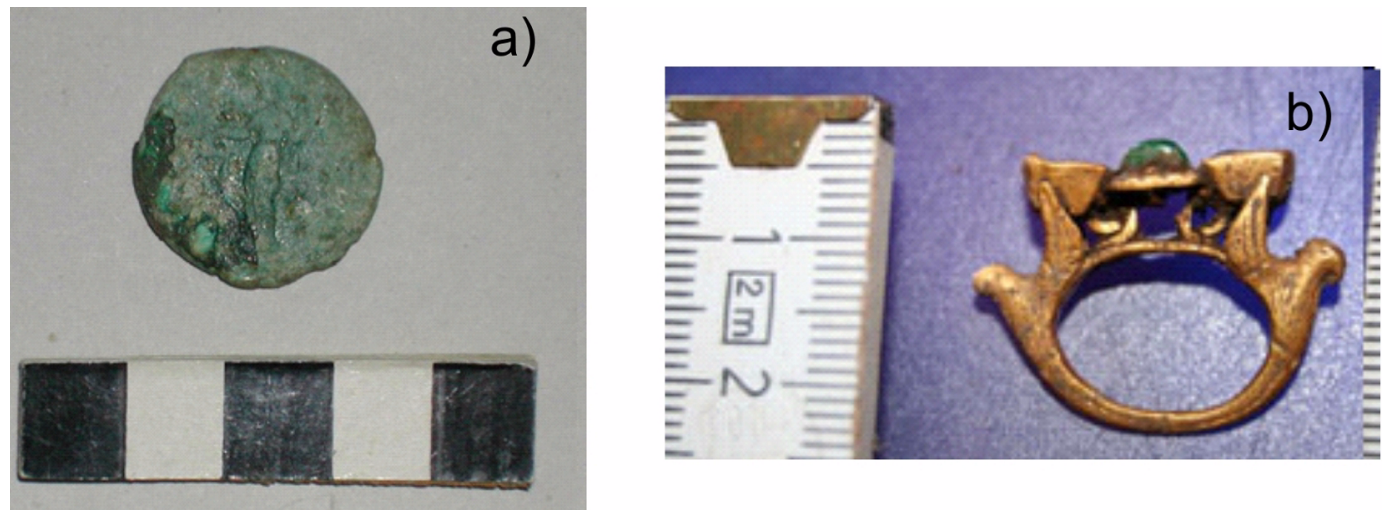

Figure 3 Some of the funerary goods found in Tomb XI and in Tomb XII: a) the coin recovered in Tomb XI (the side with the figure of the goddess Aequitas is visible); b) one of the rings recovered in Tomb XII.

Prior to chemical pretreatment, samples were mechanically cleaned with a scalpel and washed in deionized water in an ultrasonic bath for $10 \mathrm{~min}$. Ultrasonic baths were repeated several times until all macroscopic soil contamination was removed. The samples were then crushed to small fragments in a mortar. Collagen was extracted using a modified Longin method (Longin 1971), according to the following steps:

- $\mathrm{HCl} 1 \mathrm{M}$ at room temperature for about $48 \mathrm{hr}$, to remove the inorganic fraction of bone;

- $\mathrm{NaOH} 0.1 \mathrm{M}$ at room temperature for $2 \mathrm{hr}$, to purify the extracted collagen;

- $\mathrm{HCl} 1 \mathrm{M}$ at room temperature for $2 \mathrm{hr}$, to remove any $\mathrm{CO}_{2}$ absorbed from the atmosphere during the second step.

After each step, samples were rinsed with deionized water to neutral pH. Finally, the solution of the organic residue was heated at $\mathrm{pH} \sim 3$ at $80{ }^{\circ} \mathrm{C}$ for $12 \mathrm{hr}$ to collect dissolved collagen as gelatin.

When dating bone samples, the state of preservation of the bone, i.e. the quality of the extracted collagen, is of crucial importance in order to have reliable results. All our processed samples produced collagen yields higher than $1 \%$, which is reported in the literature as a safe limit for accurate dating (van Klinken 1999). Another important quality indicator is represented by the $\mathrm{C} / \mathrm{N}$ ratio: a value in the range 2.9-3.6 is considered a good indication of a well-preserved bone (De Niro 1985). As far as our samples are concerned, we have measured an average $\mathrm{C} / \mathrm{N}$ atomic ratio of 3.4 , a very acceptable collagen quality. The $\mathrm{C} / \mathrm{N}$ ratio was measured by a $\mathrm{CHN}$ elemental analyzer (ThermoFinnigan Flash EA1112), which was also used for sample combustion. The carbon dioxide originating from each sample was finally reduced to graphite following our standard procedure (Fedi et al. 2007), by reaction with hydrogen at about $600^{\circ} \mathrm{C}$, using iron as catalyst.

${ }^{14} \mathrm{C}$ concentrations were calculated correcting the measured ${ }^{14} \mathrm{C} /{ }^{12} \mathrm{C}$ isotopic ratios for isotopic fractionation $\left({ }^{13} \mathrm{C} /{ }^{12} \mathrm{C}\right.$ isotopic ratio is simultaneously measured in the AMS beam line during each run) and background, and then normalizing the corrected values to the isotopic ratio measured for a set of NIST oxalic acid II standards.

$\delta^{13} \mathrm{C}$ content of the samples extracted purified collagen was also measured by conventional mass spectrometry, using a ThermoFinnigan Elemental Analyzer EA-1108 interfaced with an isotope ratio mass spectrometer (Finnigan DeltaPlusXL) via the Conflo II interface (Finnigan MAT, Bremen, Germany). 


\section{RESULTS AND DISCUSSION}

As shown in Figure $4,{ }^{14} \mathrm{C}$ concentrations in the measured samples of each of the individuals are all consistent with one another; thus, the best estimate for ${ }^{14} \mathrm{C}$ age of the 2 humans has been calculated from their weighted average. Table 1 summarizes the average conventional ${ }^{14} \mathrm{C}$ ages and the ${ }^{13} \mathrm{C}$ values for the man in Tomb XI and the woman in Tomb XII: the agreement between the 2 individuals is clear.

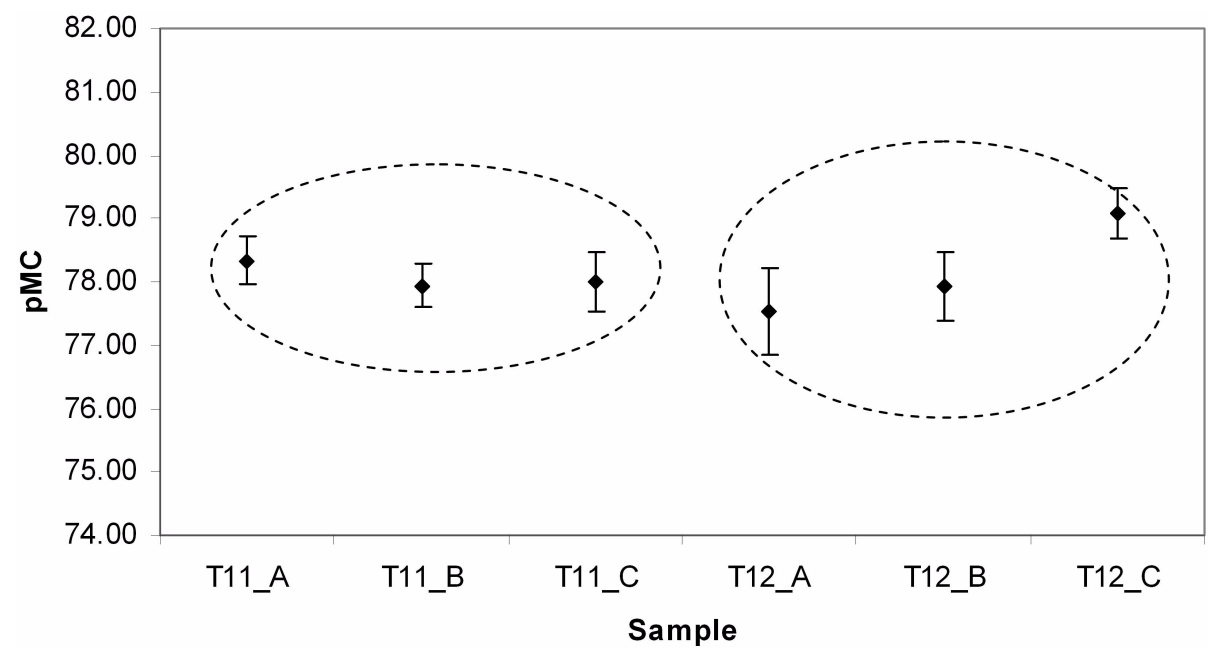

Figure $4{ }^{14} \mathrm{C}$ concentrations for all the measured samples; circles drawn in dotted lines identify samples from the same individual.

Table 1 Results of ${ }^{14} \mathrm{C}$ dating $\left({ }^{14} \mathrm{C}\right.$ concentrations and corresponding conventional ${ }^{14} \mathrm{C}$ ages) and ${ }^{13} \mathrm{C}$ measurements of bone samples. Experimental uncertainties are quoted as $1 \sigma$.

\begin{tabular}{llll}
\hline & $\mathrm{pMC}$ & $\mathrm{t}_{\mathrm{RC}}(\mathrm{yr} \mathrm{BP})$ & $\delta^{13} \mathrm{C}(\%)$ \\
\hline $\mathrm{T} 11$ & $78.09 \pm 0.23$ & $1987 \pm 25$ & $-18.0 \pm 0.2$ \\
$\mathrm{~T} 12$ & $78.48 \pm 0.29$ & $1946 \pm 30$ & $-18.6 \pm 0.2$ \\
\hline
\end{tabular}

The most probable real age time intervals are then obtained by calibration of conventional ${ }^{14} \mathrm{C}$ ages. However, when dealing with bone collagen, the calibration procedure is not be necessarily straightforward. ${ }^{14} \mathrm{C}$ content in humans depends on what they eat, in particular whether the composition of food is essentially terrestrial and/or marine. It is well known that marine carbon might appear older than terrestrial carbon, due to the marine reservoir effect. If a fairly large portion of the diet of an individual is based on fish or other marine-derived foods, his/her ${ }^{14} \mathrm{C}$ concentration in equilibrium conditions can be significantly lower than the concentration in the atmosphere. An estimation of the human paleodiet can be thus be important to improve the accuracy of bone dating (Arneborg et al. 1999). Stable carbon and nitrogen isotopes measurements are considered a good indicator of the paleodiet, as ${ }^{13} \mathrm{C}$ and ${ }^{15} \mathrm{~N}$ assume different values depending on the typology of nutrition of the individuals during their lives. ${ }^{13} \mathrm{C}$ can be associated to the consumption of either $\mathrm{C}_{3}$ or $\mathrm{C}_{4}$ plants, or of marine foods; ${ }^{15} \mathrm{~N}$ can reflect the so-called trophic level, i.e. the position of an individual in the food chain.

In the case of the 2 humans in Tombs XI and XII, we have estimated their diet on the basis of the measured carbon isotopic fractionation and by comparison with data found in the literature. They 
are characterized by $\delta^{13} \mathrm{C}$ values that are higher than typical values for a $100 \%$ terrestrial diet (based on $\mathrm{C}_{3}$ vegetation). This can be explained by assuming either a fraction of marine organisms in their diet or a terrestrial supply partly based on $\mathrm{C}_{4}$ plants. However, the latter can be excluded since most of $\mathrm{C}_{4}$ plants are found especially in tropical-warm environments. The consumption of millet might perhaps be taken into account; however, millet was not very popular in the Mediterranean region (Prowse et al. 2004; Keenleyside et al. 2009), thus, its direct uptake appears to have a very low probability. The indirect uptake can be neglected as well: in the cited papers, the authors conclude that even the use of millet as animal fodder in these areas can be excluded, since isotopic prints in the animals found in the examined sites can be explained by a $C_{3}$ terrestrial diet. On the contrary, the hypothesis of a marine fraction in the paleodiet of these 2 individuals appears to be reasonable considering their geographical position along the coast of Populonia. Measured $\delta^{13} \mathrm{C}$ values are indeed in the range reported in literature for the skeletons from the Roman Imperial age cemetery of Isola Sacra (Prowse et al. 2004), and it is reasonable to suppose that populations living in similar geographical areas had similar diets. Moreover, during Roman times, fish was considered an expensive food item (Prowse et al. 2004), suggesting that the consumption of fish and marine resources might have been restricted to elite members of the society - such as these 2 individuals, in light of the outstanding richness of the funeral equipment and of anthropological considerations.

We have thus estimated the percentage of marine diet in the 2 individuals by linear interpolation considering as endpoint values $\delta^{13} \mathrm{C}=-21 \%$ for a $100 \%$ terrestrial diet and $\delta^{13} \mathrm{C}=-12.5 \%$ o for a $100 \%$ marine diet (as in Arneborg et al. 1999). A fraction of about 30\% marine diet has been obtained.

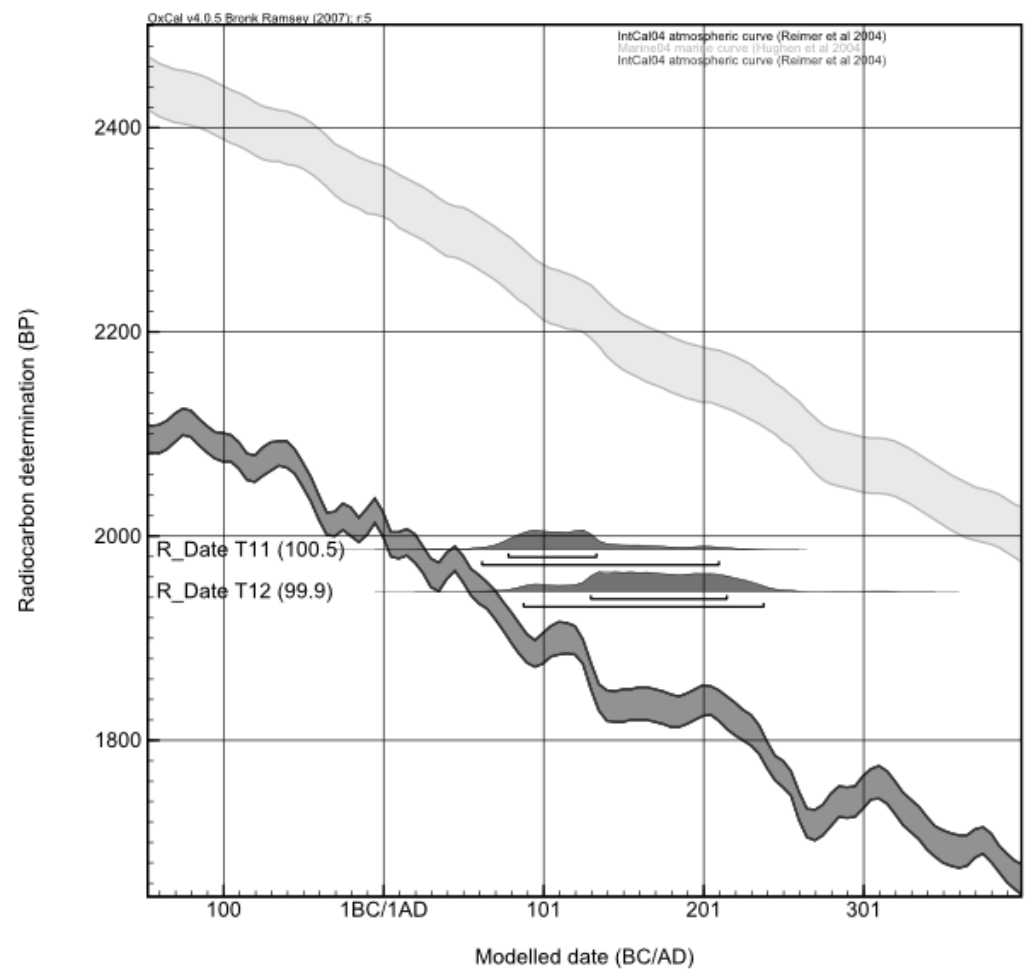

Figure 5 Distributions of probability for the true calendar ages of the 2 individuals as calculated by a mixed terrestrial/marine calibration curve (OxCal v 4.0); IntCal04 (dark gray) and Marine04 (light gray) are reported in the graph. 
Finally, the calibration of ${ }^{14} \mathrm{C}$ ages has been performed by using a mixed terrestrial/marine calibration curve obtained by interpolating IntCal04 (Reimer et al. 2004) with Marine04 (Hughen et al. 2004) (see Figure 5), according to the above-estimated percentage (OxCal v 4.0 [Bronk Ramsey 1995,2001 ) has been used).

As Figure 5 shows, the 2 individuals can be dated back to a period between the end of the 1 st century $\mathrm{AD}$ and the beginning of the 3rd century $\mathrm{AD}$, during the Roman Imperial age. This result is consistent with the already cited archaeological hypothesis that the 2 tombs belonged to the 2 nd century $\mathrm{AD}$, as deduced from the coin found in Tomb XI.

In conclusion, ${ }^{14} \mathrm{C}$ dating of the skeleton of the individuals of Tombs XI and XII proved to be a valuable instrument to obtain information about the chronology of the 2 tombs. In addition to ${ }^{14} \mathrm{C}$ measurements, we estimated the percentage of marine diet by measuring ${ }^{13} \mathrm{C}$ values of bone collagen and then used these data to calibrate the ${ }^{14} \mathrm{C}$ ages with a mixed (terrestrial-marine) calibration curve. As mentioned, the accuracy of bones dating might be further improved by measuring $\delta^{15} \mathrm{~N}$, which can lead to a better knowledge of the specific diet.

\section{ACKNOWLEDGMENTS}

We are grateful to Prof Pier Andrea Mandò (University of Florence and INFN, Florence) for the fruitful discussion during the measurements, to Prof Franco Cambi (University of Siena), for supervising the archaeological excavation of Populonia-Baratti, and to Dr Ilaria Baneschi (IGG, Istituto di Geoscienze e Georisorse, CNR, Pisa) for ${ }^{13} \mathrm{C}$ measurements by conventional mass spectrometry. This work was partially supported by the ST@RT program of Regione Toscana.

\section{REFERENCES}

Arneborg J, Heinemeier J, Lynnerup N, Nielsen HL, Rud N, Sveinbjörnsdóttir A. 1999. Change of diet of the Greenland vikings determined from stable carbon isotope analysis and ${ }^{14} \mathrm{C}$ dating of their bones. Radiocarbon 41(2):157-68.

Botarelli L, Coccoluto M, Mileti C, editors. 2007. Materiali per Populonia 6. Edizioni ETS. Pisa. In Italian.

Bronk Ramsey C. 1995. Radiocarbon calibration and analysis of stratigraphy: the OxCal program. Radiocarbon 37(2):425-30.

Bronk Ramsey C. 2001. Development of the radiocarbon calibration program. Radiocarbon 43(2A):355-63.

Cartocci A, Fedi ME, Taccetti F, Benvenuti M, Chiarantini L, Guideri S. 2007. Study of a metallurgical site in Tuscany (Italy) by radiocarbon dating. Nuclear Instruments and Methods in Physics Research B 259(1): 384-7.

Chiarantini L, Benvenuti M, Guideri S. 2006. Recenti ricerche sui processi di produzione del ferro nel Parco di Baratti e Populonia nel I millennio a.C. Rassegna di Archeologia classica e post classica, 21B 2004-2005. All'Insegna del Giglio Edizioni. Firenze. p 171-82.

De Niro MJ. 1985. Postmortem preservation and alteration of in vivo bone collagen isotope ratios in relation to palaeodietary reconstruction. Nature 317(6040): 806-9.

Fedeli F, Galiberti A, Romualdi A. 1993. Populonia e il suo territorio, profilo storico-archeologico. All'Inse- gna del Giglio Edizioni. Firenze. In Italian.

Fedi ME, Cartocci A, Manetti M, Taccetti F, Mandò PA. 2007. The ${ }^{14} \mathrm{C}$ AMS facility at LABEC, Florence. $\mathrm{Nu}$ clear Instruments and Methods in Physics Research B 259(1):18-22.

Hughen KA, Baillie MGL, Bard E, Beck JW, Bertrand CJH, Blackwell PG, Buck CE, Burr GS, Cutler KB, Damon PE, Edwards RL, Fairbanks RG, Friedrich M, Guilderson TP, Kromer B, McCormac G, Manning S, Bronk Ramsey C, Reimer PJ, Reimer RW, Remmele S, Southon JR, Stuiver M, Talamo S, Taylor FW, van der Plicht J, Weyhenmeyer CE. 2004. Marine04 marine radiocarbon age calibration, $0-26 \mathrm{cal}$ kyr BP. $R a-$ diocarbon 46(3):1059-86.

Keenleyside A, Schwarcz H, Stirling L, Ben Lazreg N. 2009. Stable isotopic evidence for diet in a Roman and Late Roman population from Leptiminus, Tunisia. Journal of Archaeological Science 36(1):51-63.

Longin R. 1971. New method of collagen extraction for radiocarbon dating. Nature 230(5291):241-2.

Prowse T, Schwarcz HP, Saunders S, Macchiarelli R, Bondioli L. 2004. Isotopic paleodiet studies of skeletons from the Imperial Roman-age cemetery of Isola Sacra, Rome, Italy. Journal of Archaeological Science 31(3):259-72.

Reimer PJ, Baillie MGL, Bard E, Bayliss A, Beck JW, Bertrand CJH, Blackwell PG, Buck CE, Burr GS, Cutler KB, Damon PE, Edwards RL, Fairbanks RG, 
Friedrich M, Guilderson TP, Hogg AG, Hughen KA, Kromer B, McCormac G, Manning S, Bronk Ramsey C, Reimer RW, Remmele S, Southon JR, Stuiver M, Talamo S, Taylor FW, van der Plicht J, Weyhenmeyer CE. 2004. IntCal04 terrestrial radiocarbon age calibra- tion, 0-26 cal kyr BP. Radiocarbon 46(3):1029-58. van Klinken GJ. 1999. Bone collagen quality indicators for palaeodietary and radiocarbon measurements. Journal of Archaeological Science 26(6):687-95. 